Artigo

\title{
Dos Jogos Olímpicos da Antiguidade às olimpíadas de matemática: a constituição de atletas
}

\author{
From the Ancient Olympic Games to the Mathematics Olympics: a constitution of athletes \\ De los Juegos Olímpicos de la Antigüedad a las Olimpiadas de Matemáticas: la constitución \\ de los atletas
}

\author{
Patrícia Lima da Silva ${ }^{1}$ \\ [0000-0002-8752-1399] \\ Claudia Glavam Duarte ${ }^{2}$ \\ [0000-0002-8608-5855]
}

\begin{abstract}
Resumo
Este artigo emerge de um estranhamento causado ao observar as olimpíadas de matemática se naturalizando nas escolas brasileiras e os estudantes sendo qualificados como atletas da matemática. Impulsionadas por tal estranhamento desenvolvemos uma digressão histórica remontando à Grécia Antiga durante o período de desenvolvimento dos Jogos Olímpicos da Antiguidade, onde destacamos o momento pitagórico e o momento platônico por darem visibilidade tanto às competições atléticas quanto à matemática. Nesse movimento usamos conceitos da filosofia da diferença para construirmos nosso caminho. Em particular, trabalhamos com o conceito de gagueira de Deleuze para variar o conceito de história de Foucault. Com as análises efetuadas sobre os Jogos Olímpicos da Antiguidade, o momento pitagórico e o momento platônico pontuamos continuidades e descontinuidades entre essas práticas e as olimpíadas de matemática da contemporaneidade. Inferimos que a constituição de atletas pode se configurar no eixo que aproxima tais práticas.
\end{abstract}

Palavras-chave: Olimpíadas de matemática. Filosofia da diferença. História. OBMEP.

\begin{abstract}
This article emerges from a strangeness caused by observing the mathematics Olympics becoming natural in Brazilian schools and the students being qualified as mathematics athletes. Driven by these issues, we developed a historical tour going back to Ancient Greece during the development period of the Ancient Olympic Games, where we highlight the Pythagorean and Platonic moments for giving visibility to both athletic and mathematical competitions. In this movement, we use concepts from the philosophy of difference to build our path. In particular, we worked with Deleuze's concept of stuttering to vary Foucault's concept of history. With the analyzes carried out on the Olympic Games of Antiquity, the Pythagorean moment and the Platonic moment, we point out continuities and discontinuities between these practices and the contemporary mathematics Olympics. We infer that the constitution of athletes can be configured in the axis that approaches such practices.
\end{abstract}

Keywords: Mathematical olympics. Difference philosophy. History. OBMEP.

1 patriciasilva@furg.br, Doutoranda em Educação em Ciências, técnica administrativa em educação, Universidade Federal do Rio Grande (FURG) - Campus Santo Antônio da Patrulha, Santo Antônio da Patrulha/RS/Brasil.

2 claudiaglavam@hotmail.com, Doutora em Educação, professora, Universidade Federal do Rio Grande do Sul (UFRGS), Campus Litoral Norte, Tramandaí/RS/Brasil. 


\section{Resumen}

Este artículo surge de una extrañeza causada por observar que las Olimpiadas de Matemáticas se vuelven naturales en las escuelas brasileñas y que los estudiantes han sido calificados como atletas de matemáticas. Impulsadas por estas preguntas, desarrollamos una digresión histórica que se remonta a la Antigua Grecia durante el período de desarrollo de los Juegos Olímpicos de la Antigüedad, donde destacamos el momento pitagórico y el momento platónico porque dan tanta visibilidad a las competiciones atléticas como a las matemáticas. En este movimiento usamos conceptos de la filosofía de la diferencia para construir nuestro camino. En particular, trabajamos con el concepto de tartamudeo de Deleuze para variar el concepto de historia de Foucault. Con los análisis realizados sobre los Juegos Olímpicos de la Antigüedad, el momento pitagórico y el momento platónico, señalamos continuidades y discontinuidades entre esas prácticas y las Olimpiadas de Matemáticas de la contemporaneidad. Inferimos que la constitución de los atletas puede configurarse en el eje que se aproxima a tales prácticas.

Palabras claves: Olimpiadas de matemáticas. Filosofía de la diferencia. Historia. OBMEP

\section{Movimentos iniciais}

Na contemporaneidade, as olimpíadas de matemática têm se tornado uma ação bastante presente na rotina escolar do Brasil. Vemos, por exemplo, a Olimpíada Brasileira de Matemática das Escolas Públicas (OBMEP) em 2019 estar presente em 99,71\% dos municípios desse país. Também têm sido frequentes as notícias nos meios de comunicação de estudantes brasileiros que vão representar o Brasil em olimpíadas internacionais de matemática e retornam com premiações.

Ao lado disso, nos deparamos com discursos que qualificam esses estudantes como "'atletas' da matemática" (BAGATINI, 2019, p. 2) ou mais enfaticamente como "verdadeiros atletas da Matemática" (INSTITUTO NACIONAL DE MATEMÁTICA PURA E APLICADA, 2017, p. 64).

Uma vez que, em nossa perspectiva de pesquisa, todo a priori é forjado historicamente, somos instigadas a pensar sobre quais movimentos históricos aconteceram e que podem ter ressonâncias, nos dias de hoje, na realização das olimpíadas de matemática. Nesta trajetória fomos movidas pela curiosidade de percebermos por que se instituíram olimpíadas de matemática e por que é possível chamar nossos estudantes de atletas desta área do saber.

Dito de outro modo, que continuidades e descontinuidades existem entre as olimpíadas gregas, voltadas ao exercício físico, e as olimpíadas de matemática, que primam pelo cognitivo ${ }^{3}$ O que se passa aí?

Somos inicialmente levadas ao período no qual aconteceram os Jogos Olímpicos da Antiguidade, intervalo formalmente compreendido do ano 776 a.C. até o ano 393 da nossa era. O que emerge num primeiro momento é o fato, já conhecido, de esses jogos serem um meio de honrar os deuses, mais particularmente, honrar Zeus.

\footnotetext{
${ }^{3}$ Cabe ressaltar que não propomos uma clivagem entre o corpo e o cognitivo, pois ambos estão presentes tanto nas olimpíadas gregas quanto nas olimpíadas de Matemática. O que observamos é o deslocamento de ênfase em uma e em outra.
} 
Com o objetivo de olhar para o lugar da matemática nesse intervalo e delimitar o nosso período de pesquisa, escolhemos analisar dois momentos pertencentes ao intervalo histórico citado acima: o momento pitagórico e o momento platônico. Eles foram escolhidos como momentos privilegiados uma vez que dão visibilidade tanto para a matemática quanto para os Jogos Olímpicos da Antiguidade que aconteciam em Olímpia, na Grécia Antiga. Nesse movimento emergem pontos de contato entre essas duas práticas, alguns dos quais, após terem sido atualizados, ressoam nas olimpíadas de matemática da contemporaneidade.

Com lentes ajustadas pela filosofia da diferença, iniciamos um caminho e juntas com Deleuze gaguejamos o conceito de

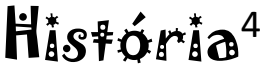

de Foucault para nessa brincadeira muito séria rirmos juntas da reescrita que fazemos de "uma transformação regulada do que já foi escrito." (FOUCAULT, 2016, p. 171).

Nesse percurso não trazemos nada de novo, mas damos visibilidade para novos agenciamentos da nossa

\section{HISTÓRIA.}

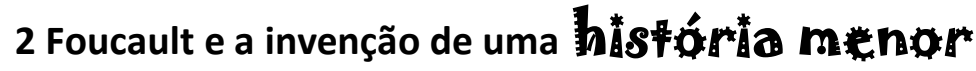

\section{HISTÓRIA,}

her (story),

\section{His (story),}

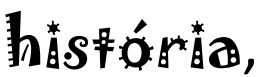

histó-ria,<smiles>[Mg][Se][Se]</smiles>

Foucault, enquanto escritor, "se torna gago da língua: ele faz gaguejar a língua enquanto tal" (DELEUZE, 2011, p. 138). Em particular, ele faz a

\section{HISTÓRIA}

oficial gaguejar e, dessa forma, a língua já não a aceita com tranquilidade.

Em cada gaguejada se desfaz uma continuidade, a fim de evidenciar que os acontecimentos históricos estão imbricados em um sistema de positividades que os produzem

\footnotetext{
${ }^{4}$ Aprendemos com a bela tese de Kátia Liége Nunes Gonçalves (2018) a brincar com a textura das palavras escritas para "Fazer a língua gritar, gaguejar, balbuciar, murmurar em si mesma" (DELEUZE, 2011, p. 141). Usamos a gagueira da autora como inspiração neste artigo.
} 
e os fazem surgir em determinada materialidade. Como afirma o filósofo: "toda esta quasecontinuidade ao nível das ideias e dos temas não passa, certamente, de um efeito de superfície" (FOUCAULT, 1999, p. XIX).

Ao suspender e desconfiar de tal efeito, Foucault nos possibilita agenciar outros sons, outras histórias, pois, com ele, a sonoridade e a textura da palavra foram alteradas. Foucault faz a língua fugir, ele não para "de desequilibrá-la, de fazê-la bifurcar e variar em cada um de seus termos" (DELEUZE, 2011, p. 144). Antes de Foucault, a língua parecia automática, sem vacilo. Estudávamos a

\section{HISTÓRIA}

das grandes civilizações, das suas guerras, das suas culturas, o nome dos seus governantes, reis, mártires...

Os historiógrafos escreviam a

\section{HISTÓRIA TRADICIONAL,}

\section{a HISTÓRIA OFICIAL,}

\section{a HISTÓRIA MAIOR.}

A história parecia não variar. Ela era generalizante e dava a impressão de ser escrita por um historiador neutro e sem interesses que relatava os grandes feitos, os feitos nobres, os feitos divinos, os sérios.

Foucault ri dessa

\section{HISTÓRIA - ria-histó -}

ao fazer uma inflexão nesse movimento, compondo arquivos com momentos que foram descartados do passado ou então discutindo acontecimentos que passaram despercebidos sem ter tido a devida importância, ou seja, "conteúdos históricos que foram sepultados, mascarados em coerências funcionais ou em sistematizações formais" (FOUCAULT, 2005, p.11).

\footnotetext{
${ }^{5}$ Sílvio Gallo (2007) se inspira no conceito de literatura menor e literatura maior criados por Gilles Deleuze e Félix Guattari na obra Kafka - por uma literatura menor para promover um deslocamento e criar o conceito de educação menor e de educação maior. Nos rastros do autor, propomos mais um deslocamento, falando em história menor e em história maior. Uma história menor que cria linhas de fuga para a própria história e uma história maior instituída, tradicional, reconhecida e legitimada.
} 
Nesse processo ele escreve uma

\section{hî̉:}

que foge dos modos até então hegemônicos de escrever a

\section{HISTÓRIA.}

Foucault "partilha com Nietzsche o ponto de vista de que a história deve ser uma atividade que busca destronar ídolos e deuses, que visa inquietar o pensamento e o poder, que se destina a libertar-nos do peso do passado, de sua repetição mecânica e acrítica" (ALBUQUERQUE JÚNIOR, 2006, p. 99).

Foucault, que não era historiador por formação, promove uma revolução na tradicional forma de escrever

\section{HISTÓRIA,}

desafiando os historiógrafos. Gaguejando a história, ele faz com que a história ria de si mesma:

história - história - historia - ria,

até o ponto em que talvez ela morra de tanto rir. Dessa forma, "Ele pratica a história ironicamente" (Ibid., p. 99).

Digamos, para resumir, que a história, em sua forma tradicional, se dispunha a "memorizar" os monumentos do passado, transformá-los em documentos e fazer falarem estes rastros que, por si mesmos, raramente são verbais, ou que dizem em silêncio coisa diversa do que dizem; em nossos dias, a história é o que transforma os documentos em monumentos e que desdobra, onde se decifravam rastros deixados pelos homens, onde se tentava reconhecer em profundidade o que tinham sido, uma massa de elementos que devem ser isolados, agrupados, tornados pertinentes, inter-relacionados, organizados em conjuntos. (FOUCAULT, 2016, p. 8, grifo do autor).

Essa maneira de transformar os documentos em monumentos é um convite para nós, que também não somos historiadoras, entrarmos nesse campo, olharmos uma massa de elementos e colocá-los em movimento. Nesse caminho, vamos observando os rastros encontrados. Já não procuramos pela origem pois sabemos que "o que encontramos no começo histórico das coisas não é a identidade ainda preservada da origem - é a discórdia entre as coisas, é o disparate" (FOUCAULT, 2017, p. 59). Vamos então inventando uma

\section{Histó-ria,}

ressaltando as suas descontinuidades, uma vez que "as continuidades são tomadas como encobrimento posterior das rupturas e dos acidentes que segmentam a história." (ALBUQUERQUE JÚNIOR, 2006, p. 99). Não se trata de ignorar algumas ressonâncias, de descartar as continuidades, mas enfatizar algumas rupturas e deslocamentos.

Iniciamos então um caminho de olhar para algumas práticas da Grécia Antiga, organizando, esquematizando e narrando alguns pontos dessas práticas potentes para 
pontuarmos ressonâncias nas olimpíadas de matemática e descontinuidades entre aquelas práticas e estas. Tal caminho foi escolhido pois nossos estudantes, na contemporaneidade, têm sido considerados "verdadeiros atletas".

\section{Os Jogos Olímpicos da Antiguidade}

Os Jogos Olímpicos, que aconteciam no Santuário de Olímpia, eram um dos quatro Jogos Pan-Helênicos que mobilizavam as diferentes pólis da Grécia Antiga. Esta, por sua vez, não era uma nação unificada como hoje. Era composta por várias cidades-estados (as pólis) que muitas vezes eram rivais, porém, possuíam a língua, a cultura e a religião em comum.

Os Jogos Olímpicos da Antiguidade têm a sua primeira edição datada do ano de 776 a.C. e foram proibidos no ano de 393 pelo imperador Teodósio I com a justificativa de serem rituais de paganismo (pois eram uma prática de honra aos deuses). Segundo Machado (2010), desde o século XII a.C. já aconteciam pequenos jogos em Olímpia e no ano de 884 a.C. foi formalizado o período de Trégua Sagrada, o qual determinava um período de suspensão das guerras para que todos pudessem viajar em segurança até o Santuário. No entanto, o registro oficial dos vencedores iniciou apenas no ano de 776 a.C., sendo este o ano formalmente considerado como início dos jogos. Naturalmente essa competição sofreu mudanças nos seus quase doze séculos. A narrativa que trazemos a seguir grifa alguns dos pontos comuns presentes nas diferentes edições desse festival:

Santuário de Olímpia, Grécia Antiga. O grande Templo de Zeus, abriga sua colossal estátua, feita de ouro e marfim com mais de 12 metros de altura, uma das Sete Maravilhas do Mundo Antigo. O Templo é rodeado por oliveiras, árvore sagrada de Zeus, que cede seus ramos para confeccionar o prêmio dos vencedores dos Jogos Olímpicos: uma coroa de oliveiras. O núcleo de Olímpia, principal centro espiritual da Grécia Antiga, é um bosque sagrado que abriga os espaços de culto religioso e os edifícios associados à administração dos jogos. Na competição apenas cidadãos homens podem competir (estrangeiros, mulheres e escravos ficam de fora), em geral oriundos das classes mais favorecidas. A pólis de Elis, pela proximidade do Santuário de Olímpia, é a responsável pela organização dos jogos, que ocorrem a cada quatro anos, e pelo envio de arautos às demais pólis anunciando a data exata da competição e o período de Trégua Sagrada. Os jogos são em honra a Zeus e as vitórias também são dedicadas ao pai de todos os deuses e mortais. Só há um vencedor em cada modalidade esportiva, o qual é compreendido como um escolhido dos deuses. A vitória não traz glória apenas para o atleta, mas também para a pólis a qual ele representa que o retribuí com reconhecimento e alimentação gratuita pelo resto da sua vida. Para a pólis, ter um cidadão seu como vencedor olímpico é uma demonstração de força para os seus inimigos e de preferência pelos deuses em relação às demais pólis. Isso traz ao mesmo tempo um respeito e um temor por parte das demais cidades-estados. 
O esporte e o culto aos deuses estavam intimamente ligados na Grécia Antiga. Uma das evidências disso são os Jogos Olímpicos da Antiguidade, que eram ao mesmo tempo festivais atléticos e manifestações artísticas que aconteciam dentro do grande Santuário de Olímpia. Eles eram uma forma de horar aos deuses, exibindo os talentos artísticos e a destreza física dos atletas. Curiosamente, os atletas competiam nus e essa era uma forma de adorar aos deuses expondo e ofertando a beleza física de cada atleta às divindades, dando visibilidade ao corpo físico. Assim, possuir um corpo jovem e atlético, que compete nos Jogos Olímpicos da Antiguidade é uma maneira de reverenciar os deuses e, talvez por este motivo, a forma de reconhecimento seja a garantia da alimentação pelo resto da vida para o vencedor.

Assim, na Grécia Antiga, se agradece, se honra, se adora aos deuses, dentre outras formas, através dos Jogos Olímpicos da Antiguidade. É o exercício do corpo que compete, que se expõe, que treina, que realiza exercícios desde muito jovem, que legitima a relação entre o homem e a divindade.

Os Jogos Olímpicos da Antiguidade hoje pertencem à uma

\section{HISTÓRIA MAIOR}

da nossa humanidade. São também parte de uma

\section{His(story)}

exclusivamente masculina, protagonizada e contada pelos homens. Nas próximas seções intentamos mostrar o lugar dos Jogos Olímpicos em dois momentos da Antiguidade e os pontos de contato entre eles e a matemática desse tempo.

\section{0 momento pitagórico}

Cerca de dois séculos após o início

\section{OFICIAL}

dos Jogos Olímpicos da Antiguidade há um acontecimento marcante na Grécia Antiga, que deixa cicatrizes na história daquela época e ressonâncias em práticas da contemporaneidade. Trata-se do que chamaremos aqui de momento pitagórico.

Com essa expressão buscamos ampliar nosso campo de visão ao contexto social, político, religioso, cultural e geográfico que gerou condições para que Pitágoras e a escola pitagórica desenvolvessem sua filosofia e sua doutrina. Dessa forma, apesar de comumente se enquadrar a vida de Pitágoras entre os anos de 570 a.C. e 495 a.C., o momento pitagórico não está limitado a este intervalo de tempo. Assim, esta é uma expressão útil para designar as diversas influências que a escola pitagórica sofreu e as que ela gerou. Com isso também buscamos escapar da armadilha de buscar um início, ou uma origem, para as práticas que abordaremos. 
É principalmente devido a Aristóteles, no seu tratado intitulado de Metafísica, que ninguém contesta a existência dos pitagóricos, no entanto o mesmo não acontece com a existência de Pitágoras, que não deixou nada escrito ${ }^{6}$.

De qualquer forma, existem três biografias tardias de Pitágoras que chegaram até nós. Aqui, usamos a escrita por Porfirio7 por ela ser "uma das fontes mais seguras e importantes da História inicial da Comunidade pitagórica." (JACQUEMARD, 2007, p. 267).

Segundo Porfirio (1987, p. 32), com Pitágoras encontramos rituais de adoração aos deuses, mantendo regularidades observadas nos jogos Olímpicos da Antiguidade. É preciso agradar os deuses, honrá-los, evitar seu furor. Pitágoras "agradava aos deuses ofertando cevada, biscoito, incenso e mirra" (Ibid., p. 45, tradução nossa). Nesse trecho, percebemos o quanto era importante reverenciar aos deuses na vida dos cidadãos daquela época. Mais do que isso, visitar os santuários sagrados fazia parte dos costumes desse momento. Sendo o Santuário de Olímpia o mais importante da Grécia Antiga, ele não deixou de ser visitado por Pitágoras. Conta-se que certa vez "Pitágoras estava com seus discípulos em Olímpia falando dos presságios, dos símbolos e dos sinais pelos quais Zeus se manifesta." (Ibid., p. 38, tradução nossa). Todas essas práticas evidenciam o quanto a escola pitagórica estava permeada pelos costumes religiosos da sua época.

Sendo os Jogos Olímpicos da Antiguidade uma prática marcante desse período histórico, não deixamos de encontrar claramente orientações de Pitágoras a esse respeito. Ele "aconselhava competir, mas não triunfar, por entender que o atleta era obrigado a suportar as fadigas e, por outro lado, evitar a inveja que decorre da vitória." (Ibid., p. 33, tradução nossa). Essa orientação demarca uma breve descontinuidade em relação às competições esportivas, que têm a vitória como objetivo. Apesar do conselho de prudência em relação ao triunfo, certa vez Pitágoras se dedicou a instruir um atleta que, seguindo os conselhos que recebeu, foi vencedor em uma Olimpíada (Ibid., p.33). Essas passagens evidenciam o quanto os pitagóricos foram influenciados por esta prática cultural do seu tempo.

A relação entre Pitágoras e os deuses não encerra por aqui, ela é ainda mais profunda. Porfirio (Ibid., p.36) relata que na Magna Grécia ${ }^{8}$ Pitágoras foi incluído entre os deuses e todos o invocavam como a um deus. Prova disto é que, certa vez um discípulo de Pitágoras e sacerdote de Apolo $^{9}$ vendo a coxa de Pitágoras afirmou que ela era de ouro (Ibid., p.40). Este fato fez com que o discípulo afirmasse que Pitágoras era o próprio Apolo.

Aqui percebemos o quanto a postura e os encantos desse personagem o levaram a ser identificado a um deus, não apenas dentro da sua seita, mas em toda a comunidade. Ademais, no que concerne ao aspecto político, sabemos que Pitágoras e seus discípulos eram tão

\footnotetext{
${ }^{6}$ Isso dá margem para que alguns pesquisadores da história da matemática, como por exemplo Roque (2012, p. 103), suspeitem da existência de Pitágoras e levantem a hipótese de que ele possa não ter existido. No entanto, foge ao escopo desse artigo ir em busca de evidências da sua existência.

7 Tivemos acesso a uma versão em espanhol dessa obra, sendo responsabilidade nossa as traduções para o português que apresentamos. Cabe acrescentar que, no caminho da nossa pesquisa, foi Foucault $(2010$, p. 303) quem primeiro nos deu a pista para olharmos para o texto de Porfírio.

${ }^{8}$ Magna Grécia era o nome atribuído a várias cidades gregas localizadas ao sul da atual Itália. A cidade de Crotona, onde se desenvolveu a escola pitagórica, pertencia a essa região.
}

${ }^{9}$ Apolo era o "filho dileto de Zeus e o mais belo entre os deuses" (CONTE, 2008, p. 171). 
admirados, que as cidades confiavam os governos a seus seguidores (Ibid., p. 55). Isso evidencia a influência ampla que a escola pitagórica exerceu.

Finalmente abordamos a dedicação de Pitágoras à matemática. Segundo Aristóteles (2012, p. 53) "os pitagóricos dedicaram-se às matemáticas ${ }^{10}$ e foram os primeiros a desenvolver essas ciências e, por meio desse estudo, vieram a acreditar que seus princípios são o princípio de tudo."

Assim, no campo da matemática, eles desenvolveram um estudo centrado nos números que os levaram a desenvolver uma "doutrina pitagórica dos números" (LIVIO, 2015, p. 33). Esses estudos chegaram à conclusão de que "as coisas existem por imitação dos números" (ARISTÓTELES, 2012, p. 58).

Uma implicação dessa identificação entre todas as coisas e os números é a de que "para os pitagóricos, Deus não era um matemático - a matemática era Deus!" (LIVIO, 2015, p. 45). Isso dentro do contexto de que o próprio Pitágoras possuía o status de um deus, insere a matemática na teia do enredo desenvolvido até aqui, dando centralidade a ela em todo esse processo. Ao se reverenciar os deuses parecia também querer se reverenciar a matemática.

Com essas passagens buscamos dar visibilidade a práticas do momento pitagórico que são muito caras aos pontos de contato que buscamos identificar entre práticas olímpicas e o desenvolvimento de uma matemática. Nesse percurso, identificamos como ponto comum os rituais de adoração aos deuses, que ora são as divindades e ora são os números e a matemática.

\section{0 momento platônico}

Passaram-se mais alguns anos e fazemos uma nova parada para analisarmos os pensamentos de Platão ${ }^{11}$ que são relevantes para os nossos objetivos. Assim como fizemos na seção anterior, aqui chamamos essa "parada" de momento platônico, ampliando o nosso olhar a diversos campos que influenciaram esse filósofo e que foram influenciados por ele.

Em Platão (2019, p.125) temos marcada a importância de respeitar aos deuses, de honrá-los, mostrando o quanto nesse momento a relação do povo grego continua permeada pela relação com as divindades. Além disso, era preciso também escutá-los através dos oráculos ${ }^{12}$, levar em conta na vida as orientações recebidas.

No momento platônico uma das maneiras de honrar aos deuses é justamente exibir o corpo atlético. Aqui, esse corpo atlético é o corpo de um jovem, um jovem que compete nos Jogos Olímpicos da Antiguidade. Além disso, para Platão os exercícios físicos também têm um importante papel para formar as virtudes de um bom cidadão. É justamente a ginástica que

\footnotetext{
${ }^{10}$ Segundo Bastos (2006, p. 12) “o termo matemática só começou a ser utilizado no século XIX. Antes, pensavase separadamente em Geometria, Álgebra e Aritmética. Alguns autores, ainda, eram mais minuciosos e chegavam a citar cada tópico da ciência matemática como uma ciência específica. Hoje, quando pensamos em ciência matemática, já estamos, aí, incluindo todos os conceitos construídos com a utilização da geometria, álgebra e aritmética, sejam isoladamente ou inter-relacionados". No entanto, o tradutor da Metafísica esclarece que para Aristóteles as ciências matemáticas envolviam "a aritmética, a geometria, a música e a astronomia." (ARISTÓTELES, 2012, p. 43).

${ }^{11}$ O nascimento de Platão costuma ser associado por volta do ano 427 a.C. e a morte por volta de 347 a.C.

12 Na primeira aula de $A$ hermenêutica do sujeito Foucault (2010) qualifica Delfos como um dos centros da vida grega, também considerado o centro geográfico do mundo, e discorre sobre os preceitos para quem fosse consultar o oráculo neste santuário.
} 
assegura a formação da coragem e do domínio (FOUCAULT, 2010, p. 384). Esse momento exalta a importância dos exercícios físicos, dando para eles uma atribuição que não encontramos no momento pitagórico, pois além de contribuir para o desenvolvimento do atleta também contribuiria para o desenvolvimento do cidadão em geral.

Assim como Pitágoras, Platão também esteve em Olímpia (KANGUSSU, 2004, p. 23), evidenciando também nesse momento a importância de reverenciar o principal centro espiritual da Grécia Antiga. Além disso, também encontramos orientações em Platão a serem seguidas para quem quiser vencer em Olímpia, mostrando a importância dessa atividade nesse momento histórico.

No texto intitulado Apologia de Sócrates, Platão (2019a) narra a defesa de Sócrates durante o seu julgamento na ação pública envolvendo os crimes de sedução da juventude e impiedade. Após Sócrates tomar ciência que fora considerado culpado pelos juízes ele deve propor uma pena alternativa à solicitada pelos acusadores, a saber, a pena de morte. Então Sócrates diz o seguinte:

[...] Ora, o que é adequado a um pobre homem que é vosso benfeitor e que necessita de ócio para exortar-vos? Nada há, homens de Atenas, tão adequado quanto tal homem receber suas refeições no pritaneu. Isso é muito mais adequado a mim do que a qualquer um de vós que haja vencido nos Jogos Olímpicos com cavalo, biga ou quadriga. O vencedor olímpico vos faz parecer felizes, enquanto eu vos faço felizes. Ademais, ele não tem em absoluto, necessidade de sustento, ao passo que eu sou um necessitado. Portanto, se me cabe propor uma pena de acordo com meu merecimento, proponho a minha alimentação no pritaneu. (Platão, 2019a, p. 66-67)

A pena substitutiva proposta por Sócrates é que ele receba de Atenas o mesmo prêmio que os vencedores olímpicos recebem, que ele receba sua alimentação gratuita custeada pela cidade no pritaneu. Nesse momento ele se coloca como sendo mais importante para Atenas do que os atletas campeões em Olímpia.

Essa passagem dá visibilidade a dois pontos importantes dos Jogos Olímpicos da Antiguidade. O primeiro deles é a importância para uma pólis de ter um atleta vencedor nas competições esportivas. Isso é tão importante ao ponto que esse cidadão não necessita se preocupar com a busca da sua alimentação, condição essa necessária para que o corpo físico sobreviva. Evidenciando assim a ênfase dessa competição no corpo.

Ao contrário do que encontramos no momento pitagórico, não encontramos no momento platônico uma associação pessoal de Platão a algo divino ou a um deus. Igualmente, não encontramos adjetivos como o de "seita" sendo atribuídos à sua Academia, esvaziando uma característica que foi marcante no momento anterior.

Porém no momento platônico também encontramos ligações entre deus e a matemática.

No diálogo Timeu, por exemplo, Platão (2010, p. 209) diz que deus usou as formas e os números para moldar o universo. Para ele, a matemática, compreendida nesse período como sendo as formas geométricas e os números, seria a ferramenta, por excelência, de construção do universo. Mais do que isso, Aristóteles explica qual é o exato lugar da matemática na teoria de Platão:

[...] além das coisas sensíveis e das Formas, existe uma classe intermediária, os objetos das matemáticas, que diferem das coisas sensíveis por serem 
eternos e imutáveis, e das Formas, por haver múltiplos objetos semelhantes das matemáticas, ao passo que cada Forma é, ela própria, única. (ARISTÓTELES, 2012, p. 58).

Dessa forma Platão resolve o problema de não conseguir enquadrar a matemática nem junto às Formas e nem junto às coisas sensíveis, criando uma classe especial para ela, um lugar único.

Para Livio (2015, p. 53), "na mente de Platão, matemática torna-se inteiramente associada ao divino.". Livio ainda traz um panorama da dedicação e influência de Platão para o desenvolvimento da matemática de seu tempo:

O filósofo e historiador do primeiro século Filodemo pinta um quadro claro: 'Naquela época, observou-se um enorme progresso da matemática, com Platão servindo como o arquiteto geral, apontando os problemas, e os matemáticos investigando-os seriamente.' Ao que o filósofo e matemático neoplatônico Próculo acrescenta: 'Platão... promoveu um grande avanço da matemática em geral e geometria em particular por causa de seu zelo por esses estudos. (Ibid., p. 48-9)

Evidentemente, Platão possui uma extensa obra e aqui trouxemos alguns recortes apenas. Com isso, intentamos grifar alguns pontos que marcam o quanto nesse período houve uma atenção especial pelo desenvolvimento da matemática e uma exaltação ao corpo atlético e aos exercícios físicos, com foco na competição olímpica e na formação de virtudes. No entanto, fica bastante evidenciado em nossos estudos que, nesse período, a matemática esteve associada ao divino.

\section{Os Jogos Olímpicos da Antiguidade e as olimpíadas de matemática: o que se passa aí?}

Percebemos que tanto o momento pitagórico quanto o momento platônico são momentos que dão visibilidade aos Jogos Olímpicos da Antiguidade que aconteciam no Santuário de Olímpia, mostrando a importância dessa competição e dando orientações para que um cidadão se tornasse um vencedor. Competir em Olímpia é uma maneira de honrar aos deuses através da exposição de um corpo físico atlético, estando nesse corpo o foco da competição.

Concomitantemente com isso, os dois momentos que nomeamos de pitagórico e platônico foram impulsores do desenvolvimento da matemática de seu tempo. No momento pitagórico temos a associação de tudo aos números, inclusive a associação dos deuses aos números. Já no momento platônico, a matemática é utilizada por deus como ferramenta para criar o universo. Essa segunda ideia, apesar de associar intimamente a matemática à divindade, não faz uma identificação entre a matemática e deus, estando bem distante de dizer que tudo é número e que consequentemente a matemática é deus. Dessa forma, a divindade emerge como ponto de contato entre os Jogos Olímpicos da Antiguidade e a matemática e percebemos que se dedicar à matemática era também uma maneira de se dedicar aos deuses, de agradar aos deuses.

Dessa forma, percebemos nesses dois momentos uma ligação entre a matemática e as olimpíadas, ligação essa que fica a cargo da relação com as divindades. 
Parece-nos que essa é uma das condições de possibilidade para que hoje seja possível utilizarmos expressões tais como, olimpíadas de matemática, treinamento para as olimpíadas de matemática e atletas da matemática ${ }^{13}$.

Segundo o professor Pedro Malagutti (ASCOM, 2015), coordenador do comitê de provas da OBMEP, as provas da OBMEP devem exigir conhecimento matemático, criatividade e raciocínio lógico. Observamos que estas qualidades são cognitivas e mentais, colocando aí o foco dessa competição.

Observamos ressonâncias na OBMEP em relação à orientação expressa de Pitágoras referente aos Jogos Olímpicos da Antiguidade, ao dar importância para a competição, e não para a vitória.

A OBMEP é uma competição entre estudantes, que incentiva a participação de todos os estudantes brasileiros matriculados entre o sexto ano do ensino fundamental e o terceiro ano do ensino médio. No entanto, não há um único vencedor para cada um dos três níveis da competição. Bem pelo contrário, em cada nível há a distribuição de dezenas de medalhas simbólicas de ouro, prata e bronze, além de centenas de certificados de menção honrosa. Além disso, a distribuição das premiações segue uma lógica que possibilita a sua distribuição em todas as Unidades da Federação (UF), valorizando a competição.

Com relação à premiação também observamos descontinuidades e ressonâncias. 0 prêmio dos Jogos Olímpicos da Antiguidade era simbólico: apenas uma coroa confeccionada com as oliveiras sagradas de Zeus. Porém, uma vitória olímpica trazia um grande prestígio e respeito para a pólis do atleta que o retribuía com alimentação gratuita durante o resto da vida, oferecendo uma sustentação ao corpo para um cidadão que obteve o destaque deste.

Já nos dias de hoje, as medalhas simbólicas oferecidas pela OBMEP trazem um grande prestígio e respeito para a escola do estudante. E como reconhecimento pelo conhecimento matemático, criatividade e raciocínio lógico dos medalhistas, estes são convidados a participar do Programa de Iniciação Científica ${ }^{14}$. Ademais, os estudantes vinculados a escolas públicas recebem uma bolsa de Iniciação Científica Jr do Conselho Nacional de Desenvolvimento Científico e Tecnológico $(\mathrm{CNPq})^{15}$ para que, como atletas da matemática, possam aprimorar e desenvolver suas habilidades cognitivas. Esta é uma importante ruptura entre essas duas práticas.

\footnotetext{
${ }^{13}$ Interessante observar que a expressão "atletas da matemática" é utilizada pela mídia para referirem-se aos medalhistas das olimpíadas de matemática. A revista Veja (2017) publicou a seguinte manchete: "Atleta da matemática - O mineiro João César Vargas quer o ouro na olimpíada internacional, que acontece no Rio em julho, antes de seguir para a universidade de Princeton". Já o jornal Gazeta Digital (2004) usa a expressão "Os atletas da matemática" como título para uma reportagem que conta a história de três adolescentes medalhistas. Um deles tem 16 anos e o outro tem 17 anos e estão concluindo o mestrado no Instituto de Matemática Pura e Aplicada (Impa). A mesma reportagem também conta a história da primeira mulher brasileira a ganhar uma medalha na olimpíada internacional.

${ }^{14}$ O Regulamento da 15a Olimpíada Brasileira de Matemática das Escolas Públicas (OBMEP 2019) prevê que "Todos os alunos medalhistas serão convidados a participar do Programa de Iniciação Científica (PIC Jr.) como incentivo e promoção do desenvolvimento acadêmico dos participantes." (OBMEP, 2019, p. 17).

15 “Aos 6.500 alunos de escolas públicas premiados na OBMEP 2019 com medalhas de ouro, prata ou bronze e matriculados em escolas públicas em 2020, será oferecida a oportunidade de participar do Programa de Iniciação Científica Jr. (PIC Jr - OBMEP). A participação no PIC inclui o recebimento de uma bolsa de Iniciação Científica Jr do Conselho Nacional de Desenvolvimento Científico e Tecnológico (CNPq)." (OBMEP, 2019, p. 18).
} 
Finalmente, observamos uma última ruptura relativa ao local onde se passam as competições. Por um lado, na Antiguidade a disputa atlética acontecia em um único lugar, o Santuário de Olímpia. Nos dias de hoje a OBMEP acontece em cada escola inscrita, ou seja, não há uma centralidade, um único local para a realização da competição. Parece-nos que temos uma pulverização das olímpias, porém com esvaziamento da relação religiosa.

\section{7 À guisa de conclusão}

Ao findar este artigo podemos inferir que nossa pretensão foi a de inserirmo-nos nos fluxos das palavras, das histórias contadas para tocar-lhes com a "afiada lâmina da suspeição irônica" (ALBUQUERQUE JÚNIOR, 2006, p. 98).

Dito com outras palavras, ao suspeitarmos de práticas e discursos naturalizados quisemos disponibilizar outros sentidos para o dito e, desta forma, liberar outras possibilidades de leitura. Nossa intenção estava firmada na ideia de que

Se continua nos interessando ficcionar o passado, é para nos dotarmos de uma contra-memória, de uma memória que não confirma o presente, mas que o inquieta; que não nos enraíza no presente, mas que nos separa dele. O que nos interessa é uma memória que atue contra o presente, contra a seguridade do presente. (LARROSA; SKLIAR, 2001, p.7).

Assim, identificamos certas ressonâncias e algumas descontinuidades entre os Jogos Olímpicos da Antiguidade e as olimpíadas de matemática. A primeira delas é a mudança de ênfase: do corpo ao cognitivo ${ }^{16}$. Enquanto na competição olímpica o foco estava na exposição do corpo atlético, nas olimpíadas de matemática o foco está no conhecimento matemático, criatividade e raciocínio lógico trazendo para o cognitivo o foco dessa competição.

A segunda é com relação à premiação, que está imbricada na mudança de ênfase. Se por um lado observamos uma ressonância em ambas as premiações serem simbólicas por outro lado temos uma ruptura na oportunidade oferecida em cada caso. Na Grécia Antiga os vencedores recebiam alimentação para o corpo físico que se expôs. Já na OBMEP, os medalhistas participam do Programa de Iniciação Científica Jr para desenvolver as qualidades cognitivas dos premiados.

Como terceiro ponto ressaltamos a pulverização das olímpias como uma importante ruptura. Os estudantes não precisam se deslocar todos a um único local para participar da olimpíada de matemática. Cada escola funciona como uma miniolímpia. Ainda dentro desse aspecto, observamos o esvaziamento da associação a um território sagrado.

O quarto ponto que grifamos é a ressonância relativa ao prestígio do vencedor para o meio em que está inserido. Na Antiguidade era uma grande honra uma pólis ter um atleta seu vencedor em Olímpia. $\mathrm{Na}$ atualidade, as escolas que possuem estudantes medalhistas nas olimpíadas de matemática gozam de um grande prestígio e destaque.

Após pontuarmos algumas ressonâncias e rupturas entre os Jogos Olímpicos da Antiguidade e as olimpíadas de matemática da contemporaneidade e nos aproximarmos da conclusão dessa escrita (que é sempre uma conclusão temporária e não definitiva) resgatamos

\footnotetext{
16 Moura (2019) efetua um estudo sobre o uso da palavra olimpíada em vários contextos e sinaliza um deslocamento entre a olimpíada moderna e a olimpíada de matemática: "O exercício analítico efetivado sobre os deslocamentos da palavra olimpíada e seus significados mostrou que a olimpíada de matemática se distancia da olimpíada moderna, pois a primeira prioriza o cognitivo e a segunda, o físico." (MOURA, 2019, p. 103).
} 
a nossa inquietação inicial: como é possível chamar nossos estudantes de atletas da matemática? Diante do estudo que apresentamos, parece-nos que essa possibilidade está relacionada à origem etimológica da palavra atleta: "A palavra atleta provém do grego athletes e por sua vez do termo aethos, que significa esforço. Atendendo a sua origem etimológica, o atleta é aquele que compete com esforço por um prêmio." (Atleta, 2016). Dessa forma os atletas da matemática são aqueles estudantes que competem com esforço por um prêmio, ainda que este prêmio seja simbólico. Parece-nos que o esforço é o ponto de ligação entre os atletas olímpicos e os atletas da matemática.

\section{Referências}

ALBUQUERQUE JÚNIOR, Durval Muniz de. Michel Foucault e a Mona Lisa ou como escrever a história com um sorriso nos lábios. In: RAGO, Margareth; VEIGA-NETO, Alfredo (Org.). Figuras de Foucault. Belo Horizonte: Autêntica, 2006. p. 97-107.

ARISTÓTELES. Metafísica. Tradução, textos adicionais e notas Edson Bini. 2. ed. São Paulo: Edipro, 2012.

ASCOM. Matemática é instrumento de igualdade, diz coordenador de provas da Obmep. 2015. Disponível em :

<http://www.mctic.gov.br/mctic/opencms/salalmprensa/noticias/arquivos/migracao/2015/07/Mate Matema_e_instrumento_de_igualdade_diz_coordenador_de_provas_da_Obmep.html?searchRef=o bobm\&tipoBusca=expressaoExata>. Acesso em: $16 \mathrm{dez} .2019$.

Atleta. Editorial Conceitos. Conceitos. São Paulo, 29 dez. 2016. Disponível em:

<https://conceitos.com/atleta>. Acesso em: 13 out. 2020.

BAGATINI, Alessandro. Olimpíadas de Matemática, altas habilidades e resolução de problemas. XIII ENEM, Brasil, 2019. Disponível em:

<https://www.sbemmatogrosso.com.br/eventos/index.php/enem/2019/paper/view/532/1921>.

Data de acesso: 19 Fev. 2020.

BASTOS, Tatiana Reis. A concretização do abstrato: história da institucionalização das ciências matemáticas. Belo Horizonte: Argvmentvm, 2006.

CONTE, Carlos Brasílio. Pitágoras: ciência e magia na Antiga Grécia. 3. ed. São Paulo: Madras, 2008.

DELEUZE, Gilles. Crítica e clínica. Tradução de Peter Pál Pelbart. 2. ed. São Paulo: Editora 34, 2011.

FOUCAULT, Michel. A arqueologia do saber. Tradução de Luiz Felipe Baeta Neves. 8. ed. Rio de Janeiro: Forense Universitária, 2016.

FOUCAULT, Michel. A hermenêutica do sujeito: curso dado no Collège de France (1981-1982). Edição estabelecida sob a direção de Francois Ewald e Alessandro Fontana, por Frédéric Gros. Tradução de Márcio Alves da Fonseca, Salma Tannus Muchail. 3. ed. São Paulo: Editora WMF Martins Fontes, 2010.

FOUCAULT, Michel. As palavras e as coisas. São Paulo: Martins fontes, 1999. 
FOUCAULT, Michel. Em defesa da sociedade: Curso do Collège de France (1975-1976). Tradução de Maria Ermantina Galvão. São Paulo: Martins Fontes, 2005.

FOUCAULT, Michel. Microfísica do poder. Organização, introdução e revisão técnica de Roberto Machado. 5. ed. Rio de Janeiro: Paz e Terra, 2017.

GALLO, Sílvio. Deleuze \& a Educação. 3. ed. Belo Horizonte: Autêntica Editora, 2007.

GONÇALVES, Kátia Liége Nunes. NOMADISMO DA EDUCAÇÃO MATEMÁTICA RIBEIRINHA: potências da multiplicidade... 141 f. Tese (Doutorado em Educação em Ciências e Matemáticas) - Instituto de Educação Matemática e Científica, Universidade Federal do Pará, Belém, 2018.

INSTITUTO NACIONAL DE MATEMÁTICA PURA E APLICADA. OBMEP 12 ANOS. Rio de Janeiro, 2017.

IZIDRO, Isabela. Atleta da matemática. Veja. [S.I.], 21 jun. 2017. Disponível em:

<https://veja.abril.com.br/educacao/atleta-da-matematica/>. Acesso em: 16 out. 2020.

JACQUEMARD, Simonne. Pitágoras e a harmonia das esferas. Tradução de Edgard de Assis Carvalho, Mariza Perassi Bosco. Rio de Janeiro: DIFEL, 2007.

KANGUSSU, Imaculada. Sobre eros no Fedro. In: SOUZA, Ricardo Timm de; DUARTE, Ricardo (Org.). Filosofia e literatura. Porto Alegre: EDIPUCRS, 2004.

LARROSA, Jorge; SKLIAR, Carlos. Habitantes de Babel: políticas e poéticas da diferença. Belo Horizonte: Autêntica, 2001.

LIVIO, Mario. Deus é matemático? Tradução de Jesus de Paula Assis. 4. ed. Rio de Janeiro: Record, 2015.

MACHADO, Raoni Perrucci Toledo. Entre o mito e a história: gênese e desenvolvimento das manifestações atléticas na Grécia antiga. 121 f. Tese (Doutorado em Educação Física) - Escola de Educação Física e Esporte, Universidade de São Paulo, São Paulo, 2010.

MOURA, Josaine de. Olimpíada: o uso da palavra em vários contextos. In: DUARTE, Claudia Glavam; MOURA, Josaine de; SANTOS, Suelen Assunção (Org.). Com(posições) pós estruturalistas em Educação Matemática e Educação em Ciências. São Paulo: Pimenta Cultural, 2019.

OBMEP. Regulamento da 15a Olimpíada Brasileira de Matemática das Escolas públicas (OBMEP 2019). 2019

Os atletas da matemática. Gazeta Digital. Mato Grasso, 23 maio 2004. Disponível em: <https://www.gazetadigital.com.br/suplementos/zine/os-atletas-da-matematica/37508>. Acesso em: 16 out. 2020.

PLATÃO. A república. Tradução, textos adicionais e notas Edson Bini. 3. ed. São Paulo: Edipro, 2019.

PLATÃO. Apologia de Sócrates. Tradução de Edson Bini. 3. ed. São Paulo: Edipro, 2019a.

PLATÃO. Diálogos V: O banquete; Mênon (ou da virtude); Timeu; Crítias. Tradução, textos adicionais e notas Edson Bini. Bauru: Edipro, 2010. 
PORFIRIO. Vida de Pitágoras. Introdução, tradução e notas de Miguel Periago Lorente. Madri: Editorial Gredos, 1987.

ROQUE, Tatiana. História da Matemática: uma visão crítica, desfazendo mitos e lendas. Rio de Janeiro: Zahar, 2012. 